\title{
Editorial
}

\section{The Journal of Neurosurgery at 70: the legacy continues}

\author{
James T. RutKa, M.D., Ph.D., F.R.C.S.C.
}

Editor-in-Chief, Journal of Neurosurgery Publishing Group, Charlottesville, Virginia; Division of Neurosurgery, The Hospital for Sick Children; and Department of Surgery, The University of Toronto, Ontario, Canada

The first issue of the Journal of Neurosurgery was published in January 1944, in response to a desire among North American neurosurgeons to establish a journal that would chronicle the significant advances taking place in the field, predominantly in North America. Interestingly, there had been a German neurosurgical journal published a few years previously in Berlin, Zentralblatt für Neurochirurgie, in 1936, but its circulation was limited, and its production cycle short lived. In 1944, the Editorial Board of the Journal was protective of its North American origin, but proud to invite select international dignitaries to serve, including Dr. A. Asenjo from Santiago, Chile, and Dr. Herbert Olivecrona from Stockholm, Sweden. At the outset, the Journal welcomed submissions of articles that demonstrated the use of new and innovative technologies in neurosurgery, in addition to literature and book reviews.

World War II was still raging in Europe during the lead-up to and at the time of the first published issue. That year, six issues of the Journal were published. In that first issue published in January 1944 (Volume 1, Number 1), we are provided with a glimpse of how neurosurgery was practiced 70 years ago. Ingraham and Bailey wrote on the use of fibrin products to promote hemostasis in the repair of dural defects; these products, and their newly engineered forms, are a quintessential part of neurosurgical practice to this day, ${ }^{4}$ Mufson and Davidoff described the occurrence of multiple meningiomas in neurosurgical patients - and foreshadowed the delineation and definition of neurofibromatosis Type II (NF-II) ${ }^{7}$ McKenzie wrote a technical note on the use of a cranial perforator and a ball bur-instrumentation that is still in use across all neurosurgical centers; ${ }^{6}$ and Shelden et al. ${ }^{9}$ published on the technique of the Lucite craniotomy as an investigative method for the direct observation of the brain -a technique, known as the cranial window, that is still being used by neurosurgeon researchers around the world. ${ }^{8,11}$

The opportunity to read, download, and cite the Journal's archival material back to and including the original issue in January of 1944 became a reality in 2008 when the Executive Committee and Board of Directors of the American Association of Neurological Surgeons (AANS) voted in favor of digitizing the Journal's back issues online. The decision to host this legacy material on the Journal of Neurosurgery Publishing Group (JNSPG) website must be construed as one of the most tangible benefits offered to AANS members, and the articles are available to other clinicians and investigators through institutional subscriptions. Issues of journal articles are now fully searchable back to 1944 and are linked to PubMed articles back to 1957 .

Just as we celebrate those articles in the inaugural issue of the Journal, so it is worth a moment to reflect on the future impact of articles being published now, 70 years later, in this, the final issue of the 2014 volume. Kodama et al. from Frankfurt am Main, Germany, describe their experience with somatosensory evoked potentials (SEPs) and motor evoked potentials (MEPs) in a series of 210 patients with infratentorial lesions. ${ }^{5}$ These techniques in neuromonitoring were not available in 1944 when posterior fossa surgery was still considered somewhat of an unchartered territory. Now, 70 years later, SEPs and MEPs have become commonplace neuromonitoring strategies throughout the world and have arguably led to better outcomes in patients. It is quite possible they will become a "standard of care" in the future for the resection of deep, central supratentorial brain tumors, large cerebral arteriovenous malformations, and intramedullary spinal cord tumors.

In a laboratory investigation that heralds the application of a "personalized medicine" approach to human brain tumors, Agnihotri and colleagues from Toronto, Canada, use gene-expression profiling to identify molecular signaling networks that have the potential to be targeted therapeutically in vestibular schwannoma. ${ }^{1}$ Interestingly, the authors demonstrated that germline-associated and sporadic schwannomas are molecularly indistinct and that the phosphoinositide 3-kinase-AKT-mammalian target of rapamycin (PI3K/AKT/mTOR) signaling networks are activated in these tumors. The latter discovery opens the possibility that vestibular schwannomas may be "druggable" tumors with dual PI3K and mTOR inhibitors, much the same as subependymal giant cell astrocytomas (SEGAs) in tuberous sclerosis have been shown to be responsive to the mTOR inhibitor, rapamycin. ${ }^{2}$ Harvey Cushing, who, throughout his career, considered vestibular schwannomas to be formidable tumors, would have been pleased to know that there may ultimately be a drug to treat these lesions.

As a final example, Gómez et al. from Madrid, Spain, have described a new prognostic score for predicting early mortality in severe head injury cases. ${ }^{3}$ They have validated and shown that the combination of the Glasgow Coma Scale (GCS) as described by Teasdale and Jennett, ${ }^{10} \mathrm{CT}$ 


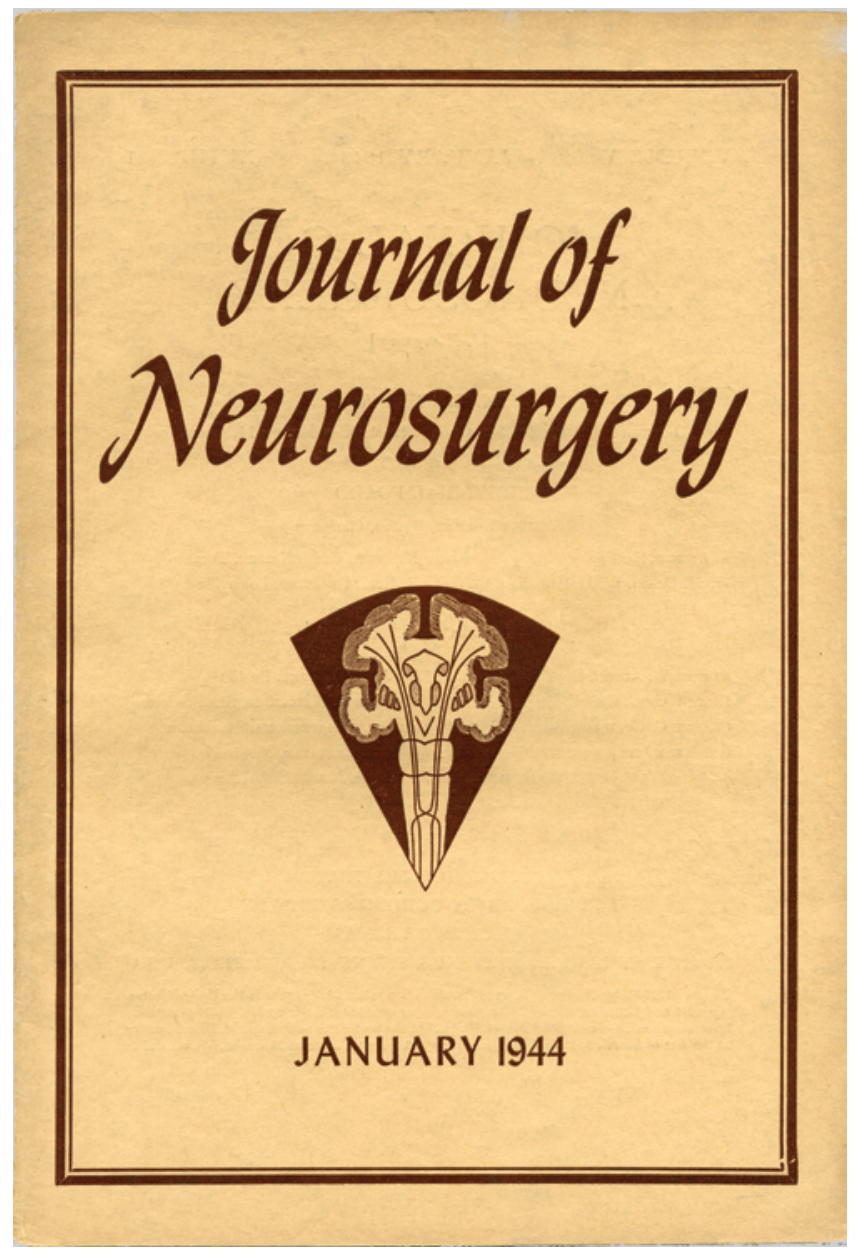

Fig. 1. Cover of the first issue of the Journal of Neurosurgery.

scanning results, and secondary injury data allowed for an improved prediction of early mortality in patients with traumatic brain injury (TBI). While the GCS has been the most reliable TBI scale used over the past 40 years, it is possible that refinements in its predictive power, as underscored by Gómez, may be extremely important in clinical trials design and in helping to shape health care policy decisions.

These 3 studies, among several others in this final issue of 2014, illustrate the proclivity of the Journal to publish high-impact research papers from centers around the world. With an impact factor of 3.227 in 2013, the highest among all specialty journals in neurosurgery, it may not be surprising that our global partners have selected the Journal of Neurosurgery in which to publish their best works.

This past year, I was delighted to lead a strategic planning process for 2015-2017 for the JNSPG. There are 5 main pillars of our plan: 1) Global position, outreach, and influence; 2) Innovations in presentation formats; 3) Collaborations and synergies with associative partners; 4) Enhancement of the efficiencies of the editorial office; and 5) Development of a sustainable business plan. As part of the new strategic plan, we worked progressively toward a redesign of the cover and internal format of all JNSPG journals. When compared to previous iterations of the Journal of Neurosurgery's cover (Fig. 1), the rede- sign, which is set to launch in January 2015, will demonstrate our strong desire to maintain an authoritative cover, and to continue to lead in content, readability, accessibility, and linkages to state-of-the-art formats for editorials, video sequences, and podcasts, among many other refinements. For the journal redesign, I should like to thank the editorial staff in Charlottesville for their unwavering engagement throughout the entire process. For those interested, our new strategic plan-"Tradition-Transition-Transformation"-can be found for review at http:// thejns.org/page/about.

I would also like to welcome Dr. Douglas Kondziolka as the new Associate Editor of the Journal and at the same moment thank Dr. Ed Oldfield for his incredible contributions over many years in this capacity. Finally, I would be remiss in not recognizing the extraordinary continued commitment of Dr. John A. Jane Sr., Editor Emeritus, in all aspects of the JNSPG's welfare. While not divulged here, I encourage all of you to examine carefully next month's issue of the Journal to see the progressive changes that I have alluded to. You will see that we are still the "white journal" but for a new era in neurosurgical publishing.

\section{References}

1. Agnihotri S, Gugel I, Remke M, Bornemann A, Pantazis G, Mack SC, et al: Gene-expression profiling elucidates molecular signaling networks that can be therapeutically targeted in vestibular schwannoma. J Neurosurg [epub ahead of print September 23, 2014. DOI: 10.3171/2014.6.JNS131433]

2. Franz DN, Leonard J, Tudor C, Chuck G, Care M, Sethuraman G, et al: Rapamycin causes regression of astrocytomas in tuberous sclerosis complex. Ann Neurol 59:490-498, 2006

3. Gómez PA, de-la-Cruz J, Lora D, Jiménez-Roldán L, RodriguezBoto G, Sarabia R, et al: Validation of a prognostic score for early mortality in severe head injury. J Neurosurg [epub ahead of print September 19, 2014. DOI: 10.3171/2014.7.JNS131874]

4. Ingraham FD, Bailey OT: The use of products prepared from human fibrinogene and human thrombin in neurosurgery: fibrin foams as hemostatic agents; fibrin films in repair of dural defects and in prevention of meningocerebral adhesions. J Neurosurg 1:23-39, 1944

5. Kodama K, Javadi M, Seifert V, Szelényi A: Conjunct SEP and MEP monitoring in resection of infratentorial lesions: lessons learned in a cohort of 210 patients. J Neurosurg [epub ahead of print September 12, 2014. DOI: 10.3171/2014.7.JNS131821]

6. McKenzie KG: A perforator and ball burr. J Neurosurg 1:5859, 1944

7. Mufson JA, Davidoff MD: Multiple meningiomas. Report of two cases. J Neurosurg 1:45-57, 1944

8. Orringer DA, Chen T, Huang DL, Armstead WM, Hoff BA, Koo YE, et al: The brain tumor window model: a combined cranial window and implanted glioma model for evaluating intraoperative contrast agents. Neurosurgery 66:736-743, 2010

9. Shelden CH, Pudenz RH, Restarski JS, Craig W: The lucite calvarium - a method for direct observation of the brain: I. The surgical and lucite processing techniques. J Neurosurg 1: $67-75,1944$

10. Teasdale G, Jennett B: Assessment of coma and impaired consciousness. A practical scale. Lancet 304:81-84, 1974

11. Zhang L, Lapierre A, Roy B, Lim M, Zhu J, Wang W, et al: Imaging glioma initiation in vivo through a polished and reinforced thin-skull cranial window. J Vis Exp [epub ahead of print], 2012

Please include this information when citing this paper: published online October 17, 2014; DOI: 10.3171/2014.9.JNS142251. 